\title{
Brønsted acid-surfactant (BAS) catalysed cyclotrimerization of aryl methyl ketone
}

\author{
Kiran Phatangare ${ }^{a}, V_{i k a s}$ Padalkar $^{a}$, Kaliyappan Murugan ${ }^{b}$ and Atul Chaskar ${ }^{b}$
}

${ }^{a}$ Institute of Chemical Technology, Matunga, Mumbai

${ }^{b}$ Department of Chemistry, National Taiwan University, 106 Taipei, Taiwan

A R T I C L E I N F O

Article history:

Received March 30, 2012

Received in Revised form

May 9, 2012

Accepted 21 May 2012

Available online

21 May 2012

\section{Keywords:}

1, 3, 5-Triaryl benzenes

Aryl methyl ketones

Brønsted acid-surfactant catalyst

(BASC)

Dodecylbenzenesulfonic acid

(DBSA)

\begin{tabular}{l} 
A B S T R A C T \\
\hline A brønsted acid-surfactant catalysed and simple, mild, metal catalyst free and chemo-selective \\
method has been developed for synthesis of 1, 3, 5-triaryl benzenes from aryl methyl ketones. \\
The advantages of this protocol subsume green and sustainable reaction medium, mild reaction \\
conditions, easy product recovery and its good yields.
\end{tabular}
method has been developed for synthesis of 1, 3, 5-triaryl benzenes from aryl methyl ketones. conditions, easy product recovery and its good yields.

\section{Introduction}

Polyphenylenes are always considered as important and interesting class of compounds due to their various useful characteristics and applications. 1, 3, 5-triaryl benzenes have been extensively employed as intermediates of buckminster fullerenes synthesis and also for the synthesis of conjugated star polyaromatics, and pharmaceuticals ${ }^{1}$. These compounds also play role as thermally stable materials and hence used as resisting materials ${ }^{2} /$ conducting polymers $^{3}$. Besides, this 1, 3, 5-triaryl benzenes are useful as electroluminescent materials $^{4,5}$ in OLEDs $^{6,7}$, electrode devices ${ }^{8}$, etc.

Owing to these facts 1,3,5-triarylbenzenes are synthesized by applying numerous strategies and using different methodologies. The most general approach of 1,3,5- triarylbenzene synthesis is triple condensation of aryl methyl ketones ${ }^{9}$ and alkynes by incorporating different catalysts such as transition metal complexes $\left(\mathrm{Nb}^{10}\right.$, * Corresponding author. Tel: +886-917352249 E-mail addresses: achaskar25@gmail.com (A. Chaskar) 
$\left.\mathrm{Co}^{11}, \mathrm{Ir}^{12}, \mathrm{Pd}^{13}, \mathrm{Rh}^{14}\right)$, acids $\left(\mathrm{HCl}^{15}, \mathrm{SiCl}_{4}{ }^{16}, \mathrm{TiCl}_{4}{ }^{17}, \mathrm{TiCl}_{3}(\mathrm{OTf})^{18}\right)$ and solid acids ${ }^{19}$. Alternative methods include cross-coupling reactions involving 1,3,5-trihalobenzenes with organometallic moieties, catalysed by metals $^{20}$. Whereas, these days the more modern and recent method practiced for production of $1,3,5-$ triarylbenzenes is by using PTSA $\left(\mathrm{TsOH} \cdot \mathrm{H}_{2} \mathrm{O}\right)^{21}$. However, in spite of their potential utility, many of these methodologies are associated with some drawbacks such as use of organic solvents and metal catalysts, harsh reaction conditions, non-recyclability of the catalyst, lower yields presumably due to the deactivation of catalyst by the water formed during the course of reaction. Considering these facts there is utmost need to develop a green methodology which could be water tolerant.

In recent years dodecylbenzenesulfonic acid (DBSA) has emerged as an ecofriendly catalyst and/or medium in organic reactions. It has received great deal of attention as a mild brønsted acid and surfactant for an array of organic transformations owing to its easy and inexpensive availability, non-toxicity, environmental benign nature, easy biodegradable nature, along with moisture and air tolerance characteristics. ${ }^{22,23}$ DBSA, an anionic surfactant, forms micelles in water. The micelles, comprising of hydrophilic and hydrophobic parts not only act as an acid catalyst but also enhance the solubility of organic substrates.

With regards to our interest in developing synthetic methodology using miceller media ${ }^{24,25}$ promoted us to investigate the utility of micelles as catalyst as well as reaction medium for triple condensation of aryl methyl ketone which readily led to corresponding 1,3,5-triaryl benzene (Scheme 1).<smiles>CC(=O)c1ccccc1</smiles>

Scheme 1. Cyclotrimerization of aryl methyl ketone

\section{Results and discussion}

An initial attempt for cyclotrimerization of acetophenone was performed in brønsted acid surfactant dodecylbenzenesulfonic acid (DBSA) and 1, 3, 5- triphenyl benzene was obtained in excellent yield. The brønsted acid surfactant first promotes sequence of aldol reactions and formed cyclophloroglucinol which on further dehydration yielded 1, 3, 5- triphenyl benzene. The equilibrium position occurs between cyclophloroglucinol and 1,3,5- triphenyl benzene in one stage and the water molecules generated during the reaction were removed from the micellar solution by hydrophobic interior of micelles, resulting into the enhancement in reaction rate (Scheme 2).

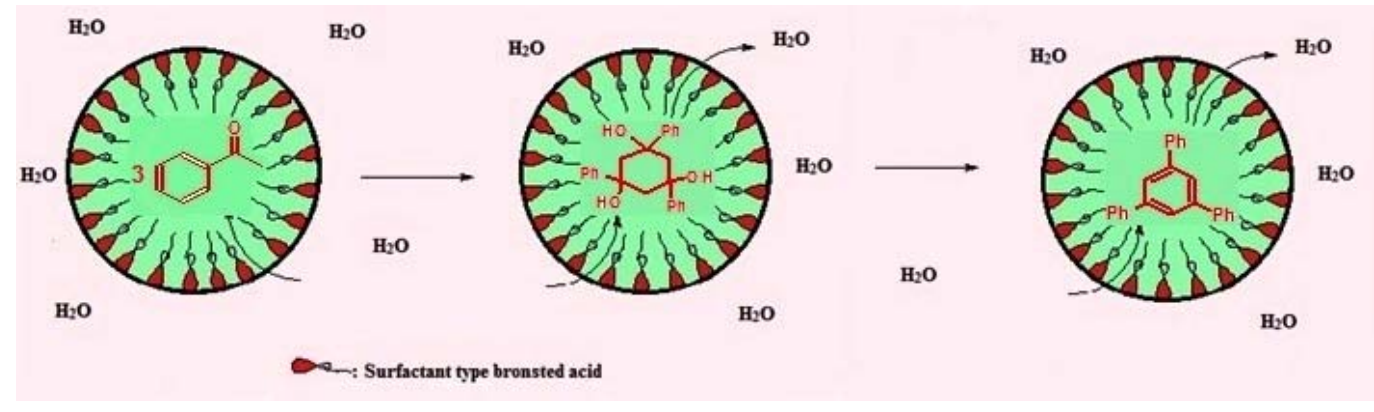

Scheme 2. Illustration of cyclization followed by dehydration in micelles.

Inspired by above obtained results, we subsequently carried out cyclotrimerization of various substituted acetophenones. To our surprise all the products were obtained in good to excellent yields. Electron donating groups lower the yields as compared to electron withdrawing groups. In case of halides, the yields increased with decreasing electronegativity. 
K Phatangare et al. / Current Chemistry Letters 1 (2012)

135

Table 1. Cyclotrimerization of aryl methyl ketones. ${ }^{a}$

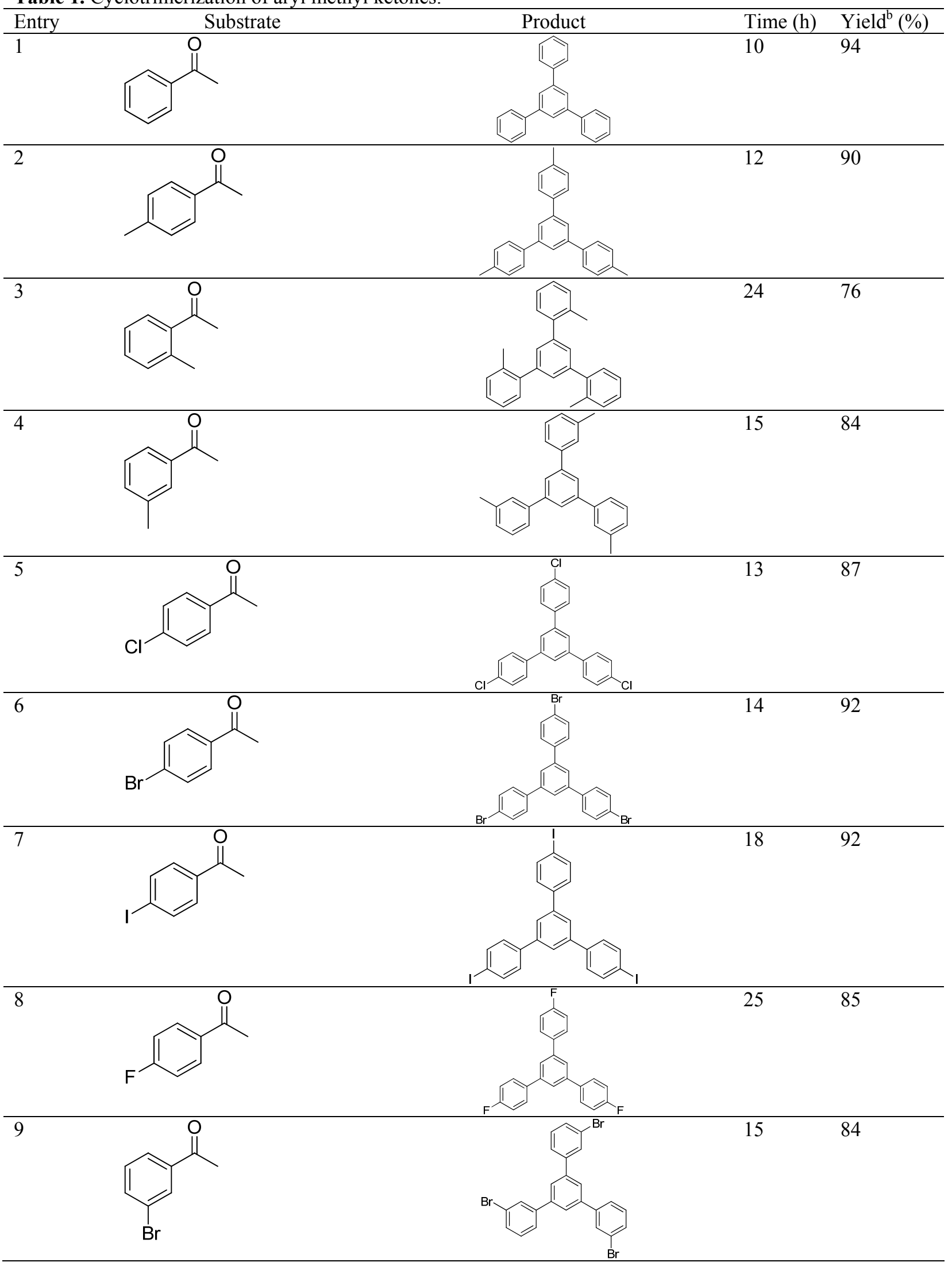




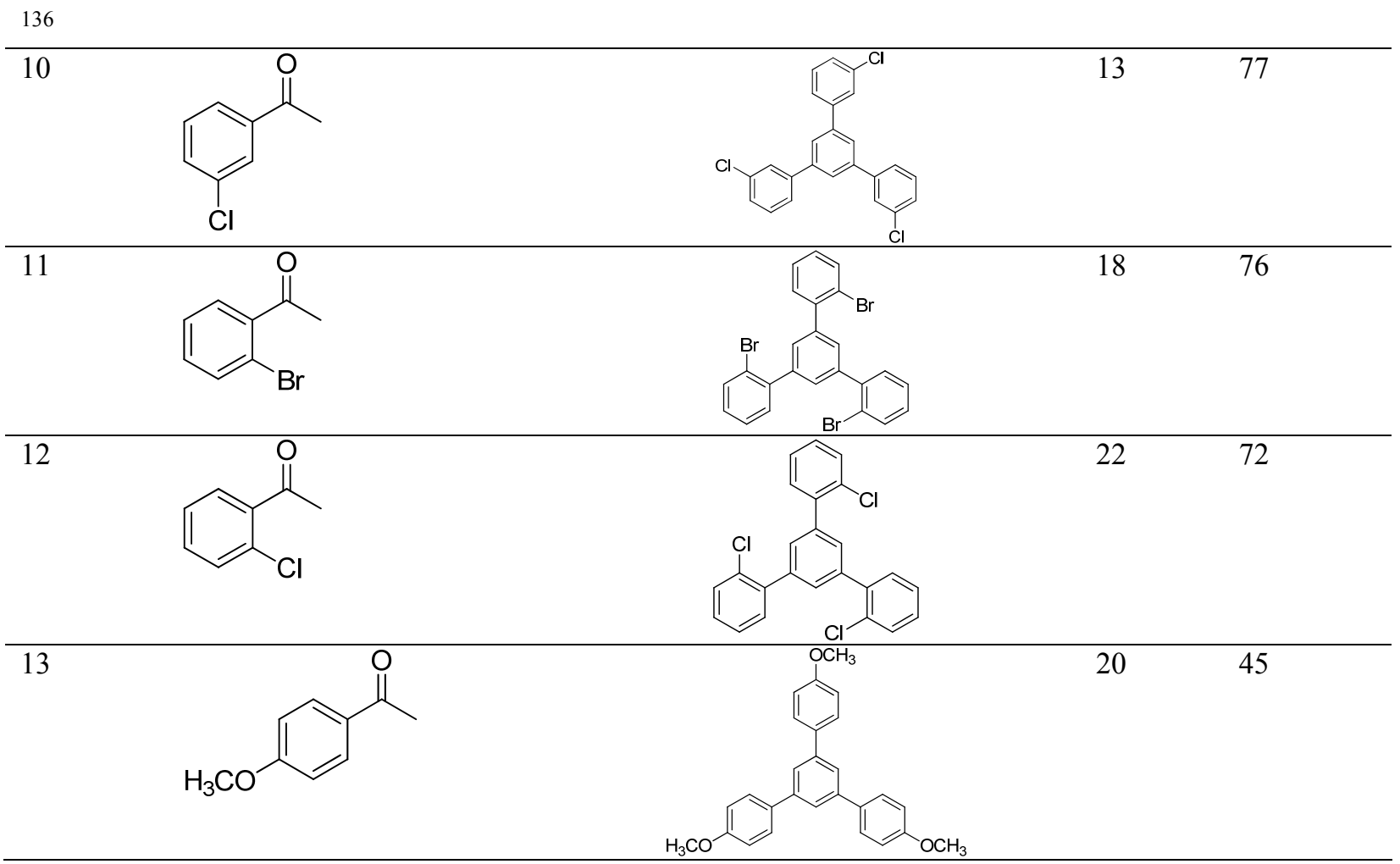

${ }^{a}$ Reaction conditions: aryl methyl ketone ( $\left.3 \mathrm{mmol}\right)$, DBSA $(3 \mathrm{mmol})$, Temperature: $130-135{ }^{\circ} \mathrm{C}$.

${ }^{\mathrm{b}}$ Isolated yields.

\section{Experimental}

All commercial reagents were used as received without purification and all solvents were of reagent grade. The reaction was monitored by TLC using $0.25 \mathrm{~mm}$ E-Merck silica gel $60 \mathrm{~F} 254$ precoated plates, which were visualized with UV light. Melting points were taken in open capillaries. The IR spectra were recorded on a PerkinElmer 257 spectrometer using KBr discs. ${ }^{1} \mathrm{H}$ NMR and ${ }^{13} \mathrm{C}$ NMR spectra were recorded on a VXR-300 $\mathrm{MHz}$ instrument using TMS as an internal standard.

\section{Typical procedure}

A mixture of acetophenone $(3 \mathrm{mmol})$ and dodecylbenzenesulfonic acid $(3 \mathrm{mmol})$ was stirred at $130-135{ }^{\circ} \mathrm{C}$ for $10 \mathrm{~h}$. After completion of reaction as indicated by TLC, the reaction mixture was extracted with ethyl acetate $(2 \times 15 \mathrm{~mL})$. The combined organic layer was washed with water, dried over magnesium sulphate, and concentrated under reduced pressure. The crude product was purified by silica.gel chromatography with hexane: ethyl acetate (9:1) as eluent to get pure compound.

Representative spectral data

1, 3, 5-Triphenyl benzene: (1)

Mp. $170-171^{\circ} \mathrm{C}$;

${ }^{1}$ H NMR (300 MHz, CDCl 3 ) $\delta: 7.82(\mathrm{~s}, 3 \mathrm{H}), 7.73(\mathrm{~d}, 6 \mathrm{H}, J=7.48 \mathrm{~Hz}), 7.51(\mathrm{t}, 6 \mathrm{H}, J=7.44 \mathrm{~Hz}), 7.42(\mathrm{t}, 3 \mathrm{H}$, $J=7.2 \mathrm{~Hz})$;

${ }^{13} \mathbf{C}$ NMR (CDCl$)$ ) $8: 142.4,141.2,128.9,127.6,127.4,125.2$;

IR $v$ (KBr): 3080, 3032, 3056, 1594, 1575, 1496, 1411, 1076, 1027, 910, 872, 765, 750, 690, 626, 610, 503, $487 \mathrm{~cm}^{-1}$; FAB-MS m/z: 319 (55), 306 (25), 228 (26), 154 (47), 136 (93), 107 (33), 89 (36), 57 (100);

HRMS-FAB (m/z): [M] $]^{+}$calcd for $\mathrm{C}_{24} \mathrm{H}_{18}, 306.1409$; found, 306.1407

\section{1, 3, 5-Tris(4'-bromophenyl)benzene: (6)}


Mp. $253-255^{\circ} \mathrm{C}$;

${ }^{1}$ H NMR (300 MHz, CDCl $)$ ) 8: 7.69 (s, 3H), 7.61 (d, 6H, J = 8.44 Hz), 7.53 (d, 6H, J = $\left.8.48 \mathrm{~Hz}\right)$;

${ }^{13} \mathbf{C}$ NMR (CDCl $\left.\mathbf{3}\right)$ 8: 141.5, 139.6, 132.0, 128.9, 125.0, 122.1;

IR v (KBr): 3081, 3057, 3032, 2921, 1594, 1575, 1496, 1411, 1076, 1027, 872, 765, 750, 690, 610, $503 \mathrm{~cm}^{-1}$;

HRMS-FAB (m/z): [M] calcd for $\mathrm{C}_{24} \mathrm{H}_{15} \mathrm{Br}_{3}, 539.8724$; found, 539.8733 .

\section{Conclusion}

As final points, the synthesis of 1, 3, 5- triaryl benzenes from a range of aryl methyl ketones has been accomplished using easily available, inexpensive and relatively non-corrosive DBSA surfactant in water as a catalyst and reaction medium. We anticipate that this eco-friendly and environmental benign protocol will be of wide synthetic and commercial interest and utility.

\section{References}

1. Elmorsy S. S., Khalil A. G. M., Girges M. M.,and Salama T. A. (1997) New routes for synthesis of branched functionalized benzenoid compounds by using tetrachlorosilane-ethanol reagent. Tetrahedron Lett., 38, 1071-1074.

2. ShirotaY. (2005) Photo- and electroactive amorphous molecular materials - molecular design,syntheses, reactions, properties, and applications. J. Mater. Chem., 15, 75-93.

3. Brunel J., Mongin O., Jutand A., Ledoux I., Zyss J., and Blanchard- Desce M. (2003) Propeller-Shaped Octupolar Molecules Derived from Triphenylbenzene for Nonlinear Optics: Synthesis and Optical Studies. Chem. Mater., 15, 4139-4148.

4. Gibson, H.W.; Ed. Handbook of Conducting Polymers; Marcel Dekker: New York, 1986. P1.

5. Kraft A., Grimsdale A. C., and Holmes A. B. (1998) Electroluminescent Conjugated Polymers-Seeing Polymers in a New Light. Angew. Chem., Int. Ed. 37, 402-428.

6. Yu W. -L., Pei J., Cao Y., Huang W., and Heeger A. J. (1999) New efficient blue light emitting polymer for light emitting diodes. Chem. Commun.1837-1838.

7. Yu W. -L., Pei J., Cao Y., Huang W., and Heeger A. J. (1999) Blue polymer light-emitting diodes from poly(9,9-dihexylfluorene-alt-co-2, 5-didecyloxy-para-phenylene). Appl. Phys. Lett. 75, 3270-3272.

8. Ono F., Ishikura Y., Tada Y., Endo M., and Sato T. (2008) Efficient Conversion of Acetophenones into 1,3,5-Triarylbenzenes Catalyzed by Bismuth(III) Trifluoromethanesulfonate Tetrahydrate. Synlett, 15, $2365-2367$.

9. Kumar A., Dixit M., Singh S. P., Raghunandan R., Maulik P. R., and Goel A. (2009) Reusable resin Amberlyst 15 catalyzed new convenient protocol for accessing arylated benzene scaffolds. Tetrahedron Lett. 50, 4335-4339.

10. Kakeya M., Fujihara T., Kasaya T., and Nagasawa A. (2006) Dinuclear Niobium(III) Complexes $\left[\left\{\mathrm{NbCl}_{2}(\mathrm{~L})\right\}_{2}(\mu-\mathrm{Cl})_{2}(\mu-\mathrm{L})\right](\mathrm{L}=$ tetrahydrothiophene, dimethyl sulfide $)$ : Preparation, Molecular Structures, and the Catalytic Activity for the Regioselective Cyclotrimerization of Alkynes. Organometallics, 25, 4131-4137.

11. Hilt G., Hengst C., and Hess W. (2008) Solvent-Dependent Regiochemical Cyclotrimerisation of Phenylacetylene with Cobalt Catalysts Containing Disulfide Ligands: A Case Study. Eur. J. Org. Chem., 2293-2297.

12. Fabbian M., Marsich N., and Farnetti E. (2004) Organoiridium compounds with bidentate phosphines as highly regioselective catalysts for alkynes cyclotrimerization. Inorg. Chim. Acta, 357, 2881-2888.

13. Lin Y.-Y., Tsai S.-C., and Yu S. J. (2008) Highly Efficient and Recyclable Au Nanoparticle-Supported Palladium(II) Interphase Catalysts and Microwave-Assisted Alkyne Cyclotrimerization Reactions in Ionic Liquids. J. Org. Chem., 73, 4920-4928.

14. Yoshida K., Morimoto I., Mitsudo K., and Tanaka H. (2008) $\mathrm{RhCl}_{3} /$ amine-catalyzed $[2+2+2]$ cyclization of alkynes. Tetrahedron, 64, 5800-5807.

15. Lyle R. E., Dewitt E. J., Nichols M. M., and Cleland W. (1953) Acid Catalyzed Condensations. I. 1,3,5Triarylbenzenes. J. Am. Chem. Soc. 75, 5959-5961.

16. Plater M. J., and Praveen M.(1997) A new synthesis of truxenone. Tetrahedron Lett. 38, 1081-1082. 
17. Li Z., Sun W. -H., Jin X., and Shao C. (2001) Triple Self-Condensation of Ketones Yielding Aromatics Promoted with Titanium Tetrachloride. Synlett 1947-1949.

18. Iranpoor N., and Zeynizaded B.(1998) $\mathrm{TiCl}_{3}(\mathrm{OTf})$ Catalyses the Efficient Conversion of Acetophenones to 1,3,5-Triaryl Benzenes. Synlett 1079-1080.

19. Lorette, N. B. (1957) Notes - Ketone Condensations Using Sulfonic Acid Ion Exchange Resin. J. Org. Chem. 22, 346-347.

20. Yoshikai N., Matsuda H., and Nakamura E. (2009) Hydroxyphosphine Ligand for Nickel-Catalyzed CrossCoupling through Nickel/Magnesium Bimetallic Cooperation. J. Am. Chem. Soc., 131, 9590-9599.

21. Zhao Y., Li J., Li C., Yin K., Yea D., and Jia X. (2010) PTSA-catalyzed green synthesis of 1,3,5triarylbenzene under solvent-free conditions. Green Chem. 12, 1370-1372.

22. Saito A., Numaguchi J., and Hanzawa Y. (2007) Pictet-Spengler reactions catalyzed by Brønsted acidsurfactant-combined catalyst in water or aqueous media. Tetrahedron Lett. 48, 835-839.

23. Shirakawa S., and Kobayashi S. (2007) Surfactant-Type Brønsted Acid Catalyzed Dehydrative Nucleophilic Substitutions of Alcohols in Water. Org. Lett. 9, 311-314.

24. Chaskar A., Padalkar V., Phatangare K., Langi B., and Shah C. (2010) Miceller-Mediated Phosphomolybdic Acid: Highly Effective Reusable Catalyst for Synthesis of Quinoline and Its Derivatives. Synth. Commun. 40, 2336-2340.

25. Pawar B., Padalkar V., Phatangare K., Nirmalkar S., and Chaskar A. (2011) Miceller media accelerated Baylis-Hillman reaction. Catal. Sci. Technol. 1, 1641. 